\title{
Intraepithelial Nerve Fibers Project Into the Lumen of the Larynx
}

Manuel Lima-Rodrigues, MD; Rui Nunes, MD, PhD; Armando Almeida, PhD

Objectives/Hypothesis: Studies on the morphology and location of the sensory receptors in the laryngeal mucosa have resulted in insufficient and sometimes conflicting data. In the present study the authors analyzed the distribution and morphology of sensory nerve plexuses and terminal fibers in the laryngeal mucosa of the rat. Study Design: Two groups of Male Wistar rats were used in this laboratory study; the larynx of the first group were used to analyse the sensitive innervation of its epithelium, whereas the larynx of the second group (controls) were tested for the specificity of the antibodies used. Methods: The larynges of the animals were entirely removed after perfusion, and coronal or horizontal sections were immunoprocessed for further randomized analysis of the mucosa. Primary afferents were detected by immunoreaction to two widely recognized markers of sensory nerves, calcitonin generelated peptide and substance $P$, and visualized using diaminobenzidine as a chromogen. Results: The nerve plexuses were more densely distributed in the dorsal half of the vocal folds and in the laryngeal aspect of the epiglottis. Dense networks of fine fibers with many varicosities en passant, immunoreactive for both calcitonin gene-related peptide and substance $P$, occurred in the lamina propria and along the epithelial thickness. Calcitonin gene-related peptideimmunoreactive and substance P-immunoreactive fibers extended across the epithelium and projected to the laryngeal lumen itself, reaching the space between the cilia. Conclusion: The projection of intraepithelial nerve fibers into the lumen of the larynx indicates that in the absence of mucus, nerve endings may be exposed and thus receive direct stimulation from airborne substances. Furthermore, it suggests that the laryngeal mucosa of the rat may constitute an experimental model for studying the direct activation or manipulation of

Presented at the 16th World Congress of OtorhinolaryngologyHead and Neck Surgery, Sydney, Australia, March 2-7, 1997.

From the School of Health Sciences (M. L-R., A.A.), Life and Health Sciences Research Institute, University of Minho, Braga, Portugal, and Faculty of Medicine (R.N.), University of Oporto, Porto, Portugal.

Supported by FCT project POCTI/NSE/46399/2002, FEDER and Grünenthal Foundation.

Editor's Note: This Manuscript was accepted for publication December 15, 2003.

Send Correspondence to Manuel Lima Rodrigues, MD, Escola de Ciências da Saúde, CP-II, Piso 3, Universidade do Minho, Campus de Gualtar, 4710-057 Braga, Portugal. E-mail: mlrodrigues@ecsaude.uminho.pt primary afferents at the periphery and neurogenic inflammation. Key Words: Substance P, calcitonin gene-related peptide, primary afferents, laryngeal mucosa, light microscopy, intraepithelial.

Laryngoscope, 114:1074-1077, 2004

\section{INTRODUCTION}

The laryngeal sensory system can initiate a wide range of reflexes with significant physiological effects related to body functions, namely, bronchial-pulmonary defense. This system interacts with components of the autonomic nervous system, as shown by the laryngeal reflex occurring in response to mechanical stimulation of the mucosa. The main innervation of the mucosa of the pharynx and larynx results from the superior laryngeal branch of the vagus nerve, although other cranial nerves, such as the trigeminal and glossopharyngeal nerves, may also be involved. ${ }^{1}$ Although the central origin of the laryngeal innervation and the local distribution of major nerve trunks are well documented, few and conflicting data are known about the fine innervation of the laryngeal wall in different animal species. ${ }^{2}$

The sensory innervation of the larynx has long been known to be located in the mucosa. ${ }^{3}$ Myelinated and unmyelinated fibers reaching the epithelium derive from a plexus in the submucosa, have numerous varicosities along their extension, and terminate as free axonal endings. ${ }^{4}$ This nervous plexus was shown to be rich in substance $\mathrm{P}(\mathrm{SP})^{5}$ and calcitonin gene-related peptide (CGRP) ${ }^{6,7}$ two neuropeptides implicated in sensory innervation, ${ }^{8-10}$ because of their key role in the transmission of nociceptive information to the central nervous system. ${ }^{11}$

The larynx sensory fibers do not reach the surface of the epithelium in humans, which suggests that mucosal irritants do not stimulate directly the primary fibers of the laryngeal mucosa. ${ }^{12}$ This anatomical feature was not recorded in other species either, ${ }^{2}$ including in the rat, ${ }^{13}$ where fibers were described (using fluorescence microscopy) as only reaching the epithelium. Interestingly, a few sensory fibers were shown to reach the lumen of human nasal mucosa. ${ }^{12}$ The objective of the present study was to review the morphology and location of the network of intraepithelial primary afferents immunoreactive to CGRP and SP in the laryngeal mucosa of the rat using bright-field light microscopy. 


\section{MATERIALS AND METHODS}

Five female rats (weight, 60-100g; age range, 20-40 d) were obtained from the Wistar Han colony of Charles Rivers Company (Barcelona, Spain). Animals were perfused under anesthesia (35\% chloral hydrate intraperitoneally) through the ascending aorta with $100 \mathrm{~mL}$ $0.1 \mathrm{~mol} / \mathrm{L}$ phosphate-buffered saline (PBS) followed by $1000 \mathrm{~mL}$ Zamboni fixative (2\% paraformaldehyde and $1.5 \%$ picric acid).

The larynx was removed and immersed in the same fixative for 4 hours at $4^{\circ} \mathrm{C}$, followed by an overnight sucrose bath $(30 \%$ sucrose in $0.1 \mathrm{~mol} / \mathrm{L}$ phosphate-buffered saline). Coronal and horizontal frozen sections were cut in a cryostat at $50 \mu \mathrm{m}$ and processed for immunocytochemical study. Alternate sections were incubated overnight at $4^{\circ} \mathrm{C}$ with rabbit anti-CGRP (1:4000) (Amersham) or rabbit anti-SP (1:40000) (Peninsula Laboratories) anti-sera in PBS with $0.3 \%$ triton $\mathrm{X}-100$ (PBST). After rinsing in PBST, the sections were incubated with biotinylated goat anti-rabbit (1:200) (Vector Laboratories) in PBST for 1 hour, washed in PBST, and incubated with avidin-biotin complex (ABC) (1:200) (Vector) in PBS for 1 hour. After rinsing in $\mathrm{PBS}$ and $0.1 \mathrm{~mol} / \mathrm{L}$ tris- $\mathrm{HCl}$ buffer $(\mathrm{pH} 7.4)$ the antigen-antibody reaction was visualized in a solution containing 10 mg diaminobenzidine (DAB) (Sigma Chemical Company) and $4 \mu \mathrm{L}$ $\mathrm{H}_{2} \mathrm{O}_{2}$ in $20 \mathrm{~mL}$ tris- $\mathrm{HCl}$ buffer. The immunostained sections were dehydrated, cleared in xylene, mounted in Entellan (Merck) and analyzed by means of bright-field light microscopy.

\section{RESULTS}

An extremely dense plexus of CGRP-immunoreactive nerve fibers was present in the laryngeal epithelial surface of the rat (Figs. 1-3). The nerve plexus was particularly abundant along the vocal folds, with a greater fiber density in the dorsal half, which decreased progressively in the ventral direction (Fig. 1). The CGRP innervation was also rich in the laryngeal aspect of the epiglottis (Fig. 3C).

The intraepithelial network is derived from nerve trunks abutting the epithelial deep surface from the underlying connective tissue of the lamina propria (Fig. 2A). The plexus is evenly distributed across the epithelial thickness with the immunoreactive fibers exhibiting a typical dotted appearance because of successive round varicosities appearing en passant along the fibers (Figs. $2 \mathrm{~B}$ and $3 \mathrm{~A})$. It is important that the fiber endings crossed the most superficial epithelial cell layer and protruded from the upper epithelial surface to the respiratory lumen itself, reaching the free space among the cilia (Figs. 2 and 3A).

Immunostaining for SP depicted an intraepithelial nerve plexus with an overall location similar to that of CGRP fibers, but with a lower density and with fewer varicosities along the fibers (Fig. 4). It is important that the superficial axonal endings also protruded through the epithelium surface and reached the laryngeal lumen (Fig. 4).

\section{DISCUSSION}

\section{Innervation of Laryngeal Epithelium}

It is known that in the rat there is a plexus of nonmyelinated sensory nerve fibers in the airway epithelium, especially at the basal level, with projections distributed toward the tight junctions near the lumen but not reaching it. ${ }^{13,14}$ However, in our study, a great number of CGRP fibers and SP fibers showing a dotted appearance because of successive round en passant varicosities were shown clearly to protrude to the airway lumen among the cilia of the apical membrane of the cells lining the laryngeal epithelium. To

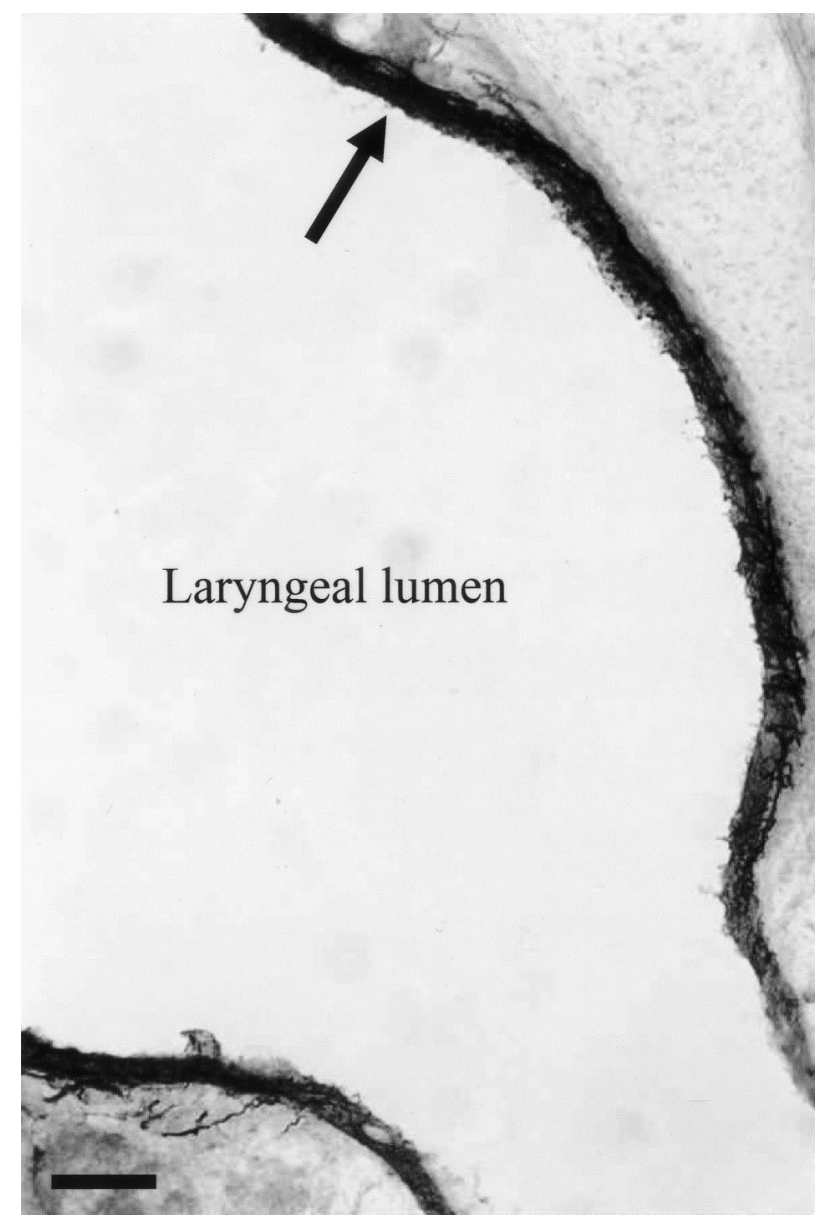

Fig. 1. Low-magnification microphotograph of the vocal fold showing the epithelial surface with the calcitonin gene-related peptideimmunoreactive plexus (arrow). Scale bar: $500 \mu \mathrm{m}$.

the best of our knowledge, this is a new anatomical observation on the sensitive innervation of the larynx, which has not been described in the literature for the rat, human, or other species. In comparison with another study performed in the rat, ${ }^{13}$ our results may reflect any combination of the following: 1) the use of much younger animals (weight, $60-100 \mathrm{vs.}$ $250-400 \mathrm{~g}$ ), 2) differences in the animal strain used (Wistar vs. Sprague-Dawley), or 3) differences in the experimental protocol followed (visualization of sensory fibers by bright field vs. fluorescent light microscopy).

The present data may help in understanding how the airborne substances can stimulate the mucosa. They suggest that in the absence of mucus the fibers are exposed and easily stimulated by irritating stimuli, for example, those caused by local inflammatory agents or exogenous irritants, such as tobacco smoke. Thus, the rat larynx may constitute a good model for the study of the action of inflammatory, degenerative, and neoplastic factors on the sensory innervation of the respiratory system. An electron microscopic study to show the relation between the apical membrane of lining epithelial cells and these free nerve endings should be undertaken in the rat. Electron microscope studies performed in humans ${ }^{15}$ and $\operatorname{dog} \mathrm{s}^{16}$ showed that SP-immunoreactive and CGRP-immunoreactive nerve fibers did not reach the respiratory lumen but terminated 

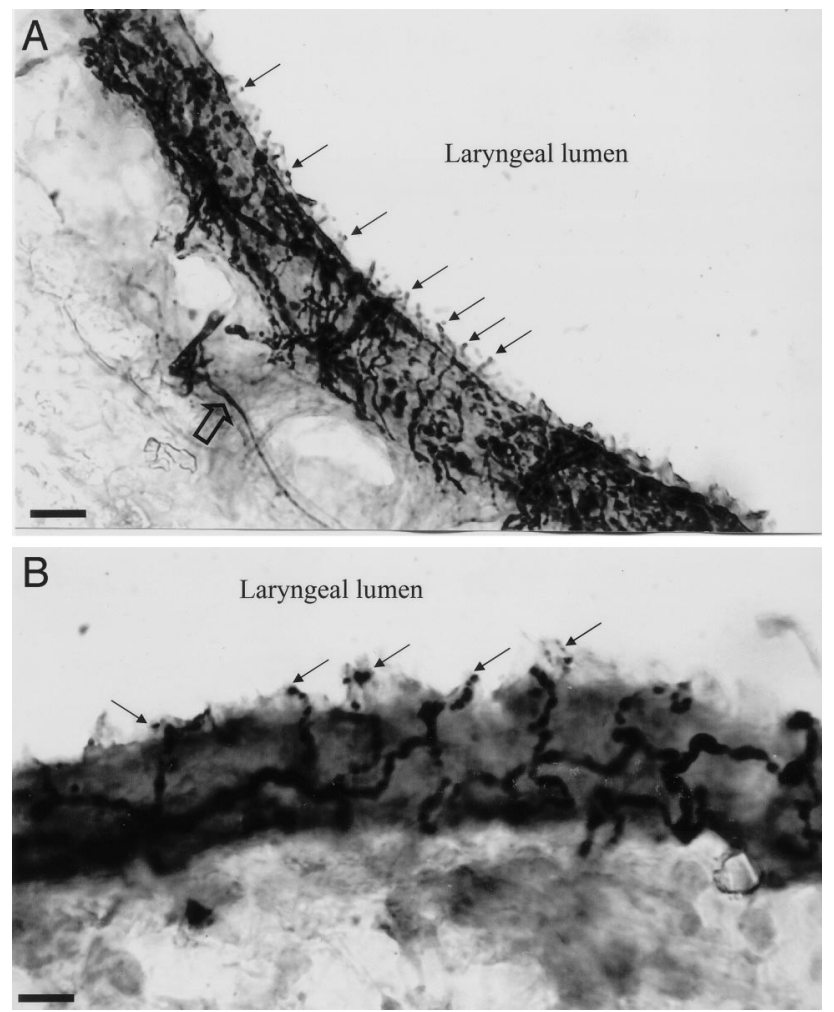

Fig. 2. Intermediate (A) and high (B) magnifications showing the intraepithelial vocal fold network of calcitonin gene-related peptideimmunoreactive (CGRP-IR) nerves from, respectively, the posterior and anterior epithelia. (A) The nerve trunks entering the plexus from the underlying lamina propria (open arrow) are evident. (A and B) The CGRP-IR terminal fibers with round en passant varicosities reaching the apical surface of the epithelium and protruding into the laryngeal lumen itself (small arrows). Scale bars: 7.5 (A) and 4 (B) $\mu \mathrm{m}$.

just under the epithelial junctional complexes that fuse the apical portion of the lateral cellular membranes of superficial epithelial cells.

In humans, a few fibers were shown to reach the surface of the epithelium in the nasal mucosa and the subepithelial excretory ducts of laryngeal mucous glands, but not the laryngeal lumen itself. ${ }^{12}$ Neuroepithelial bodies, groups of neuroendocrine cells, but not the fibers that enervate them, were shown to be located frequently at airway openings and protrude into it. ${ }^{17}$ Moreover, in the larynx the fibers enervating neuroepithelial bodies were not CGRP-positive or SP-positive. ${ }^{12}$

\section{Calcitonin Gene-Related Peptide-Immunoreactive and Substance P-Immunoreactive Sensitive Fibers}

The visceral sensory neurons of the vagus and glossopharyngeal nerves that enervate the laryngeal mucosa have cell bodies located in the nodose and petrosal ganglia, respectively. ${ }^{2,18}$ The innervation of the larynx has been studied with the aid of immunocytochemistry, and several regulatory peptides were shown in the primary afferents of the laryngeal and tracheal mucosa: CGRP and SP, tyrosine hydroxylase (TH), vasoactive intestinal peptide (VIP), and neuropeptide $\mathrm{Y}(\mathrm{NPY})$ in cats $^{6,19,20}$; SP and CGRP in $\operatorname{dogs}^{21}$;
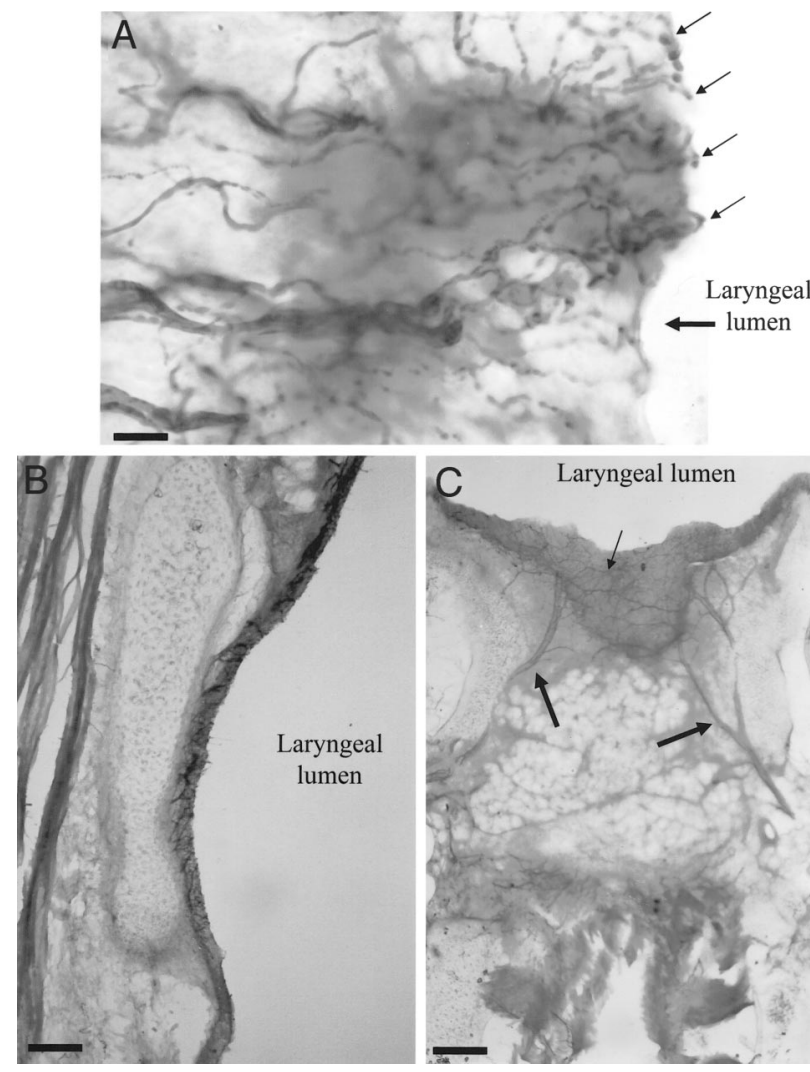

Fig. 3. The laryngeal intraepithelial calcitonin gene-related peptideimmunoreactive (CGRP-IR) nerve plexus. (A) Detail of the apical surface of the epithelium showing fibers and axonal buttons protruding into the laryngeal lumen (arrows). (B) Decreasing density of the CGRP-IR fiber network from the dorsal to ventral surface of the vocal fold epithelium. (C) Laryngeal aspect of the epiglottis intraepithelial plexus (small arrow). The bilateral CGRP-IR terminal fiber trunks of the superior laryngeal nerve (large arrows) are evident. Scale bars: 1.25 (A), 500 (B), and 800 (C) $\mu \mathrm{m}$.

NPY, VIP, SP, and CGRP in rats ${ }^{13,22}$; and VIP, NPY, SP, and CGRP in the human larynx. ${ }^{7}$ However, CGRP and SP are considered to be the main putative neurotransmitters in the laryngeal primary afferent system. In the human mucosa the characteristic corpuscular fibers running underneath and within the epithelium contained only SP and CGRP. ${ }^{7}$ In the canine nodose ganglion, the percentages of CGRP-immunoreactive $(81,5 \%)$ and SP-immunoreactive $(24,5 \%)$ neurons were much higher than those immunoreactive to other peptides. ${ }^{9,21}$ A comparative study using immunocytochemical and tract-tracing techniques concluded that the density of the laryngeal sensory nerve fibers in the human and the dog was similar to that in the cat, and the regional distribution and density of SP-immunoreactive and CGRP-immunoreactive fibers showed almost the same distribution pattern as the sensory fibers showed with the use of neuroanatomical tracing techniques. ${ }^{2}$

Although the distribution pattern of CGRPimmunoreactive and SP-immunoreactive fibers was similar, suggesting an overlapping distribution, we found that SP-immunoreactive fibers were fewer in number than CGRP-immunoreactive fibers. This finding suggests that CGRP is the most important peptide that occurs in the 


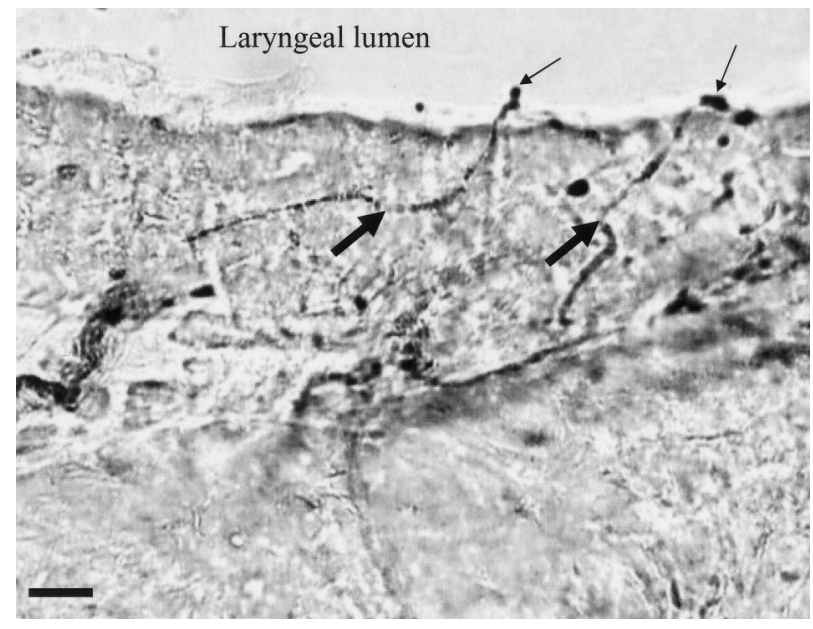

Fig. 4. Substance P-immunoreactive fibers in the laryngeal mucosa. The terminal buttons of these fibers reach the apical surface of the epithelium and protrude into the laryngeal lumen itself (arrows). Scale bar: $7.5 \mu \mathrm{m}$.

laryngeal epithelium, which is in accordance with results obtained previously in the dog. ${ }^{21}$ Our study in the rat showed a more extended area occupied by the CGRPstained fibers, which indicates that a fiber component containing exclusively CGRP may occur in the rat mucosa. However, a similar density and distribution of CGRPimmunoreactive and SP-immunoreactive fibers in the laryngeal epithelium were referred in the $\mathrm{rat}^{13}$ and humans. ${ }^{7}$ Once more, this result, which differs from that obtained in the study of Domeij et al. ${ }^{13}$ in the rat, might reflect differences in the strain and in the age of the animals used or in the experimental protocol followed, or both (as mentioned earlier in the "Discussion" section).

As in other areas of the periphery, the high concentration of SP-immunoreactive and CGRP-immunoreactive fibers in the laryngeal epithelial lining indicates that they may consist of nociceptive sensory endings. ${ }^{2}$ In fact, both neuropeptides were shown to be present in part of the $\mathrm{C}$-fibers and $\mathrm{A} \delta$-fibers of primary afferents mediating the transmission of nociceptive information from the periphery to the spinal or trigeminal dorsal horns of the central nervous system. ${ }^{11}$ In the rat, denervated (vagotomy) animals and capsaicin-treated animals (capsaicin destroys most C-fiber primary afferents) have shown a strong or complete decrease in the number of CGRP fibers and SP fibers. ${ }^{4,13}$ In accordance with data obtained for other species, ${ }^{2}$ the dorsal half of the vocal folds and the laryngeal aspect of the epiglottis are more densely innervated, which suggests that these areas are more important for sensory reception in the rat larynx.

\section{CONCLUSION}

The anatomical data observed in the present study indicate that in the larynx of the rat the nociceptive endings of SP-immunoreactive and CGRP-immunoreactive primary afferents project directly to the lumen of the respiratory tract and thus may be directly activated by noxious stimulation of the larynx and stimulate cough reflex or neurogenic inflammation.

\section{Acknowledgments}

The authors thank Professor Antonio Coimbra, PhD, for scientific advice.

\section{BIBLIOGRAPHY}

1. Widdicombe J. Reflexes of the upper respiratory tract. In: Fishman AP, Cherniack NS, Widdicombe JG, Geiger SR, eds. Handbook of Physiology. Bethesda, MD: The American Physiological Society; 1986:363-394.

2. Yoshida Y, Tanaka Y, Hirano M, Nakashima T. Sensory innervation of the pharynx and larynx. Am J Med 2000; 108:51S-61S.

3. Storey AT. A functional analysis of sensory units innervating epiglottis and larynx. Exp Neurol 1967;20:366-383.

4. Bradley R. Sensory receptors of the larynx. Am J Med 2000; 108:47S-50S.

5. Hisa Y, Sato F, Fukui K, Ibata Y, Mizukoshi O. Substance P nerve fibers in the canine larynx by PAP immunohistochemistry. Acta Otolaryngol (Stockh) 1985;100:128-133.

6. Tanaka Y, Yoshida Y, Hirano M, Morimoto M, Kanaseki T. Distribution of SP- and CGRP-immunoreactivity in cat's larynx. J Laryngol Otol 1993;107:522-526.

7. Hauser-Kronberger C, Hacker G, Albegger K, et al. Autonomic and peptidergic innervation of the human larynx. HNO 1994;42:89-98.

8. Yamamoto Y, Atoji Y, Susuki Y. Innervation of taste buds in the canine larynx as reveled by immunohistochemistry for the various neurochemical markers. Tissue Cell 1997;29:339-346.

9. Yamamoto Y, Atoji Y, Susuki Y. Neurochemical markers in the nervous plexus of the canine glottis. J Auton Nerv Syst 1998;71:111-119.

10. Yamamoto Y, Atoji Y, Susuki Y. Calbindin D28kimmunoreactive afferent nerve endings in the laryngeal mucosa. Anat Rec 2000;259:237-247.

11. Millan MJ. The induction of pain: an integrative review. Prog Neurobiol 1999;57:1-164

12. Hauser-Kronberger C, Hacker G, Franz P, Albegger K, Dietze $O$. CGRP and substance $\mathrm{P}$ in intraepithelial neuronal structures of the human upper respiratory system. Regulatory Peptides 1997;72:79-85.

13. Domeij S, Dahlqvist A, Forsgren S. Regional differences in the distribution of the nerve fibers showing substance $\mathrm{P}$ and calcitonine gene-related peptide-like immunoreactivity in the rat larynx. Anat Embryol (Berl) 1991;183:49-56.

14. Widdicombe J. Afferent receptors in airways and cough. Respir Physiol 1998;114:5-15.

15. Villaverde R, Pastor LM, Calvo A, Ferran A, Sprekelsen C. Nerve endings in the epithelium and submucosa of human epiglottis. Acta Otolaryngol (Stockh) 1994;114:453-457.

16. Ohgi R, Maeyama T, Shin T. Electron microscopic immunohistochemical study of intraepithelial nerve fibers in the canine larynx. Auris Nasus Larynx 1994;21:44-52.

17. Yu J. An overview of vagal receptors. Acta Physiol Sin 2002; 54:451-459.

18. Huang F, Zhuo H, Sinclair C, Goldstein ME, McCabe JT, Helke CJ. Peripheral deafferentation alters calcitonin gene-related peptide mRNA expression in visceral sensory neurons of the nodose and petrosal ganglia. Mol Brain Res 1994;22:290-298.

19. Rha KS, Majima Y, Sakakura Y, Yasui Y, Nakano K, Ishihara A. Distribution of substance $\mathrm{p}$ immunoreactive nerve fibers in the tracheal submucosal gland of cats. Ann Otol Rhinol Laryngol 1994;103:222-226.

20. Tanaka Y, Yoshida Y, Hirano M. Precise localization of VIP-, NPY-, and TH-immunoreactivities of cat laryngeal glands. Brain Res Bull 1995;36:219-224.

21. Hisa Y, Tadaki N, Uno T, Okamura H, Taguchi J, Ibata Y. Neuropeptide participation in canine laryngeal sensory innervation. Ann Otol Rhinol Laryngol 1994;103:767-770.

22. Domeij S, Dahlqvist A, Forsgren S. Studies on colocalization of neuropeptide Y, vasoactive intestinal peptide, catecholamine-synthesizing enzymes and acetylcholinesterase in the larynx of the rat. Cell Tissue Res 1991;263: $495-505$. 